\title{
ESTRUTURA FITOSSOCIOLÓGICA E GRUPOS ECOLÓGICOS EM FRAGMENTO DE floresta estacional Semidecidual, Uberaba, Minas Gerais, Brasil
}

\author{
Olavo Custódio Dias Neto ${ }^{1}$, Ivan Schiavini ${ }^{2}$, Sérgio de Faria Lopes ${ }^{2}$, \\ Vagner Santiago do Vale ${ }^{2}$, André Eduardo Gusson ${ }^{2} \&$ Ana Paula de Oliveira ${ }^{2}$
}

\section{RESUMo}

(Estrutura fitossociológica e grupos ecológicos em fragmento de floresta estacional semidecidual, Uberaba, Minas Gerais, Brasil) Estudos em florestas estacionais semideciduais (FES) são necessários para caracterizar a estrutura e verificar a formação de padrões, possibilitando também comparações de composição florística entre fragmentos. Este estudo foi realizado em um fragmento de FES, em Uberaba, MG, na qual foram demarcadas 25 parcelas de $20 \times 20 \mathrm{~m}$, amostrando-se todos os indivíduos arbóreos vivos com circunferência do tronco a $1,30 \mathrm{~m}$ do solo $\geq 15 \mathrm{~cm}$. Foram analisados os parâmetros fitossociológicos usuais e, também, a similaridade florística entre a área de estudo e outras áreas de FES. Foram amostrados 805 indivíduos, representados por 90 espécies, sendo Micrandra elata (Euphorbiaceae) a espécie mais importante na comunidade, seguida de Galipea jasminiflora (Rutaceae). Espécies pioneiras tiveram baixa representatividade na amostra. Além disso, a presença de indivíduos de grande porte, de espécies pouco comuns, associada à área basal de 45,8 $\mathrm{m}^{2}$ ha${ }^{1}$, são evidências de se tratar de floresta madura, em bom estado de conservação, representativa da condição original. A análise de similaridade entre esta e outras áreas florestais remanescentes demonstrou a formação de quatro grupos distintos, associados a regiões geográficas, com indícios de que florestas em bom estado de conservação são mais semelhantes entre si.

Palavras-chave: distribuição espacial, floresta mesófila, similaridade florística.

\section{Abstract}

(Phytosociology and ecological groups in seasonal semideciduous forest fragments, Uberaba, Minas Gerais, Brazil) Studies on seasonal semideciduous forests (FES) are required in order to characterize the structure and verify the formation of patterns, also comparing the floristic composition among fragments. A remnant of FES, in Uberada, MG, was assessed by surveying twenty-five plots $(20 \times 20 \mathrm{~m}$ each) totalizing one hectare. All living trees with circumference at breast height $(1.30 \mathrm{~m}$ above the ground $) \geq 15 \mathrm{~cm}$ were recorded. common phytosociological parameters and floristic similarity with other FES remnants were calculated. A total of 805 individuals were surveyed, representing 90 species. Micrandra elata (Euphorbiaceae) was the most important species in the community, followed by Galipea jasminiflora (Rutaceae). Besides the low relative density of pioneer species, the high basal area $\left(45.8 \mathrm{~m}^{2} \mathrm{ha}^{-1}\right)$ and the peculiar flora are evidences of a mature and well preserved forest. The similarity analysis resulted in four distinct groups, related to geographical regions, and apparently, floristic similarity is higher among well preserved forests.

Key words: spatial distribution, mesophytic forest, floristic similarity.

\section{INTRODUÇÃO}

Os ecossistemas florestais no Brasil são diversos e complexos, fatos que estão atrelados à sua grande área física e diversidade de climas e solos (Leitão-Filho 1987). No estado de Minas Gerais, as fisionomias florestais se estendiam por uma vasta região do centro-sul e leste do estado (IBGE 1993). Dentre as formações vegetais de Minas Gerais estão as florestas estacionais semideciduais (FES), caracterizadas pela sazonalidade climática que determina a perda foliar (20 a 50\% de deciduidade) dos indivíduos arbóreos dominantes, em resposta à deficiência hídrica ou queda de temperatura nos meses mais frios e secos (Veloso et al. 1991). As florestas semideciduais ocorrem na forma de manchas, principalmente na região do cerrado do Brasil central (Rizzini 1979). Essas formações coincidem com solos férteis e úmidos,

Artigo recebido em 06/2009. Aceito para publicação em 10/2009.

${ }^{1}$ Universidade Federal de Uberlândia, Instituto de Biologia, R. Ceará s/no ${ }^{\circ}$ bloco 2D, sala 57, Campus Umuarama, 38400-902, Uberlândia, MG, Brasil. Autor para correspondência: olavonneto@yahoo.com.br

${ }^{2}$ Universidade Federal de Uberlândia, Programa de Pós-graduação em Ecologia e Conservação de Recursos Naturais, Campus Umuarama, bloco 2D, 38400-902, Uberlândia, MG, Brasil. 
características de grande atrativo para a agropecuária, e, assim, foram drasticamente reduzidas nas regiões do sul e leste de Minas Gerais (Eiten 1982). Esta redução fragmentou as florestas, sendo este um dos fatores que comprometem a reprodução das espécies raras, que podem desaparecer em alguns fragmentos (Silva \& Soares 2003).

Da mesma forma como ocorreu em outros estados brasileiros, onde o processo de ocupação e exploração remonta ao período colonial, a cobertura florestal primitiva do estado de Minas Gerais foi reduzida a remanescentes esparsos. Atualmente, a maioria dessas fisionomias vegetais encontra-se bastante alterada pela retirada seletiva de madeira ou mais preservada em áreas onde a topografia dificulta o acesso (Oliveira-Filho \& Machado 1993). Segundo o mapa da Flora Nativa e dos Reflorestamentos de Minas Gerais, em 2006, 33,8\% do território de Minas Gerais mantinha cobertura vegetal nativa e, para a floresta estacional semidecidual, esse percentual era de 8,9\% (Scolforo et al. 2006). Apesar da crescente fragmentação, cada remanescente de FES apresenta particularidades históricas e grau de preservação diferentes, refletidos em sua composição florística e estrutura, tornando sua conservação de elevada importância para a manutenção da biodiversidade (Santos \& Kinoshita 2003). Essas florestas apresentam alta diversidade florística e possuem flora arbórea bem estudada, quando comparada com a de outras formações vegetais (Leitão-Filho 1992). Entretanto, poucos são os estudos sobre a estrutura fitossociológica destas florestas no Triângulo Mineiro (e.g. Araújo \& Haridasan 1997; Rosa \& Schiavini 2006; Gusson et al. 2009).

Também é relevante o conhecimento das síndromes de dispersão em florestas, já que a dispersão é um processo ecológico estratégico na comunidade florestal e seu estudo tem grande importância no entendimento das variáveis envolvidas na organização da comunidade (Yamamoto et al. 2007), da mesma forma que os grupos sucessionais existentes.

Apesar da reconhecida variação espacial na estrutura e na composição das florestas estacionais semideciduais, parte-se da premissa de que é possível inferir sobre o estado de conservação de uma dada área, com base no porte dos indivíduos da vegetação e do grupo sucessional predominante, em número de espécies e indivíduos. Assim, os objetivos deste estudo foram: 1) descrever a composição florística e estrutura fitossociológica de um trecho de floresta estacional semidecidual e analisar seu estado de conservação; 2) classificar as espécies arbóreas em diferentes guildas de regeneração e síndromes de dispersão; 3 ) avaliar, com base nos dados levantados em campo, a importância ecológica da área, baseada na sua diversidade, na proporção de espécies e indivíduos nos diferentes grupos ecológicos e na heterogeneidade da vegetação, quando comparada com estudos realizados no mesmo tipo de formação florestal.

\section{Material e Métodos}

\section{Área de estudo}

$\mathrm{O}$ estudo foi realizado em um fragmento de floresta estacional semidecidual situada na reserva legal da Fazenda Sucupira-Caçu, que está localizada a $12 \mathrm{~km}$ do centro da cidade de Uberaba, Minas Gerais, ao norte no município. O fragmento é constituído por uma área contínua de 70 ha, caracterizado por uma extensa área de floresta estacional semidecidual, bordeada, por um lado, por uma estreita faixa de cerradão com no máximo cinco metros de largura e pelo outro lado pela mata de galeria, também estreita, nas margens do córrego Água Bonita (1940'13", 1940'43”'S e 48 $01^{\prime} 44^{\prime \prime}, 48^{\circ} 02^{\prime} 25^{\prime}$ 'O). O trecho de FES situa-se em terreno com topografia plana, com leve declividade junto ao córrego. O trecho de floresta estacional semidecidual apresenta poucos indícios de perturbação antrópica, demonstrando ser a vegetação bem conservada e representativa da condição original. No entorno do fragmento observam-se estradas, pastagens e plantações de soja e cana-deaçúcar, além de alguns pequenos fragmentos isolados de cerradão, com fortes alterações antrópicas. 
O clima da região é do tipo Aw, segundo a classificação de Köppen (1948), marcado por duas estações bem definidas, uma quente e chuvosa, que se estende de outubro a março, e a estação seca, de abril a setembro. A média anual de temperatura, no município de Uberaba, apresenta-se entre máxima de $30,3^{\circ} \mathrm{C}$ e mínima de $17,5^{\circ} \mathrm{C}$ e a precipitação pluviométrica média dos anos de 1995 a 2004 foi de $1630 \mathrm{~mm}$ (Abdala 2005).

\section{Levantamento de dados}

Para a realização do levantamento fitossociológico foi escolhido um trecho representado apenas pela floresta estacional semidecidual, distante cerca de $50 \mathrm{~m}$ da borda do fragmento e $200 \mathrm{~m}$ da margem do córrego, onde foram instalados cinco transectos de 100 metros de comprimento por $20 \mathrm{~m}$ de largura, distantes $20 \mathrm{~m}$ um do outro. Cada transecto foi dividido em cinco parcelas contíguas, com dimensões de $20 \times 20 \mathrm{~m}$ cada.

Em cada parcela foram registrados, amostrados, coletados e identificados todos os indivíduos arbóreos vivos com CAP circunferência, à altura de $1,30 \mathrm{~m}$ acima da superfície do solo, maior ou igual a $15 \mathrm{~cm}$ (CAP $\geq 15 \mathrm{~cm}$ ). A altura de cada indivíduo foi estimada utilizando-se o podão de coleta (14 m) como referência e, acima desta altura, por estimativa visual. As espécies foram classificadas em famílias de acordo com Angiosperm Phylogeny Group II (APG II 2003). As espécies foram identificadas em campo e, quando isto não foi possível, foi coletado material botânico, encaminhado para especialistas ou identificado por comparação com material do Herbário da Universidade Federal de Uberlândia (HUFU). Material testemunho de todas as espécies amostradas foi coletado, preparado e encaminhado ao HUFU para registro e depósito.

Os parâmetros fitossociológicos analisados foram: densidade relativa (DR), dominância relativa (DoR)e frequência relativa (FR), utilizados na composição do valor de importância (VI) para espécies. Foram calculadas a densidade e área basal total, além dos índices de Shannon e Equabilidade para a comunidade. Para os cálculos, foi utilizado o programa FITOPAC SHELL (Shepherd 2007).

\section{Similaridade florística}

Como base de comparação com a flora arbórea do fragmento estudado foram selecionados 15 outros estudos em FES, todos realizados na Região Sudeste do Brasil, e com critério de inclusão semelhante.

Para comparação da composição florística entre as áreas foi confeccionada uma matriz de presença/ausência de espécies. Foram retiradas dessa análise as espécies presentes em somente uma das áreas amostradas, no intuito de priorizar a busca por semelhanças e não por diferenças florísticas entre os fragmentos comparados. Para essa comparação foi utilizado apenas o nível taxonômico de espécies, sendo eliminadas aquelas sem identificação completa. Utilizando-se a matriz de presença/ausência foi calculado o coeficiente de similaridade de Sørensen (Brower et al. 1998). Os valores calculados para similaridade foram utilizados para produzir o dendrograma de classificação, utilizando-se a média de ligação de grupo (UPGMA) como método de agrupamento. Estas análises foram realizadas com o uso do programa FITOPAC SHELL (Shepherd 2007).

\section{Grupos sucessionais e síndrome de dispersão}

Em relação aos grupos sucessionais, as espécies foram classificadas com base em Gandolfi et al. (1995) e na experiência de campo dos autores deste estudo (baseada em observações sobre condições ambientais de ocorrência de algumas espécies, tanto na área em estudo quanto em outras áreas já analisadas na região). Quanto às síndromes de dispersão, foi consultada a bibliografia para classificação das espécies, acrescida de observações de campo.

\section{Resultados e Discussão}

\section{Descrição e análise fitossociológica}

Foram amostrados 805 indivíduos, pertencentes a 35 famílias, 77 gêneros e 90 
espécies (Tab.1). Apenas duas espécies foram identificadas apenas ao nível de família.

As espécies com um só indivíduo na área amostrada representaram $32,2 \%$ da riqueza da comunidade. As famílias com maior riqueza foram: Fabaceae, com 17 espécies (19\%); Myrtaceae e Meliaceae, com oito espécies (9\%); Rubiaceae, com seis espécies (7\%); e Annonaceae, com quatro espécies (4\%) (Tab.1). Entretanto, as famílias com maior número de indivíduos foram: Rutaceae $(17,7 \%)$, Euphorbiaceae (14,9\%), seguidas de Annonaceae (11,4\%), Meliaceae $(10,8 \%)$ e Fabaceae (6,2\%). Dessas, apenas Euphorbiaceae esteve presente em todas as parcelas amostradas, devido à ampla distribuição de Micrandra elata no fragmento. Estudos realizados por Vale (2008), Silva \& Soares (2003), Silva et al. (2003) e Paula et al. (2004), em levantamentos florísticos realizados em florestas estacionais semideciduais, relataram que as famílias com maior densidade e riqueza foram Fabaceae, Meliaceae e Myrtaceae, o que demonstra a importância dessas famílias em florestas estacionais semideciduais.

Neste estudo, oito famílias foram responsáveis por 53 espécies $(58,9 \%$ do total da comunidade) e 585 indivíduos (72,6\%). Tal resultado está dentro do padrão encontrado em outras áreas remanescentes desta formação florestal, em que um pequeno número de famílias abrange mais da metade das espécies amostradas, como observado por Gandolfi et al (1995) e Vale (2008).

\section{Estrutura fitossociológica}

As dez espécies mais importantes somam $61,9 \%$ do IVI total e representam $66,7 \%$ da abundância da comunidade arbórea (Tab. 1). Em florestas tropicais a maioria das espécies ocorre em baixa densidade, não sendo incomum que 5 a 10 espécies representem 50\% do valor de importância (Hartshorn 1980). As espécies de maior VI na comunidade apresentam características estruturais diferentes: Micrandra elata destaca-se com altos valores de densidade e dominância relativas; Galipea jasminiflora e Unonopsis lindmanii destacam-se pela maior densidade e freqüência relativas e Cariniana estrellensis se destaca pela alto valor de dominância relativa. Dessa maneira, pode-se dizer que cada espécie ocupa o espaço horizontal na floresta de uma forma diferente, sugerindo estratégias de vida distintas.

Micrandra elata foi a espécie com o maior VI $(74,7)$, mais que o dobro do valor alcançado pela espécie seguinte na ordenação, G. jasminiflora, com 25,1. Esse valor do VI para $M$. elata deve-se não só ao fato de a espécie abranger 14,6\% dos indivíduos amostrados, mas também às grandes dimensões alcançadas por vários de seus indivíduos, resultando no alto valor para dominância relativa $(53,5 \%)$. Somente em estudos realizados por Araújo et al. (1997) a espécie $M$. elata foi bem representada na comunidade (com densidade de 123 ind. ha ${ }^{-1} \mathrm{e}$ VI de 27,08). Por essa razão não se pode afirmar que a ocorrência dessa espécie em florestas semideciduais da região do Triângulo Mineiro seja comum. Existe, então, uma grande variação espacial na composição e abundância das espécies arbóreas nesse tipo de formação vegetacional, onde cada fragmento apresenta particularidades, com diferentes espécies alternando-se quanto à dominância e à frequência, o que aumenta a importância dos remanescentes para fins de conservação da diversidade florística.

O valor calculado para o índice de diversidade de Shannon foi de 3,33 e para a equabilidade foi de 0,73 . O índice de diversidade encontrado na FES da Fazenda Sucupira-Caçu está dentro da faixa de variação para esse tipo de formação vegetal, que é de 2,41 a 4,23 (Lopes et al. 2002; Vale 2008) e equabilidade um pouco abaixo de valores encontrados nos estudos dos mesmos autores, que ficaram entre 0,78 a 0,81 .

Micrandra elata, Cariniana estrellensis e Hymenaea courbaril, que são espécies secundárias tardias, obtiveram os maiores valores para dominância relativa. Essa dominância relativa de poucas espécies de grande porte é um indicativo importante para assinalar o estágio de maturidade desta 


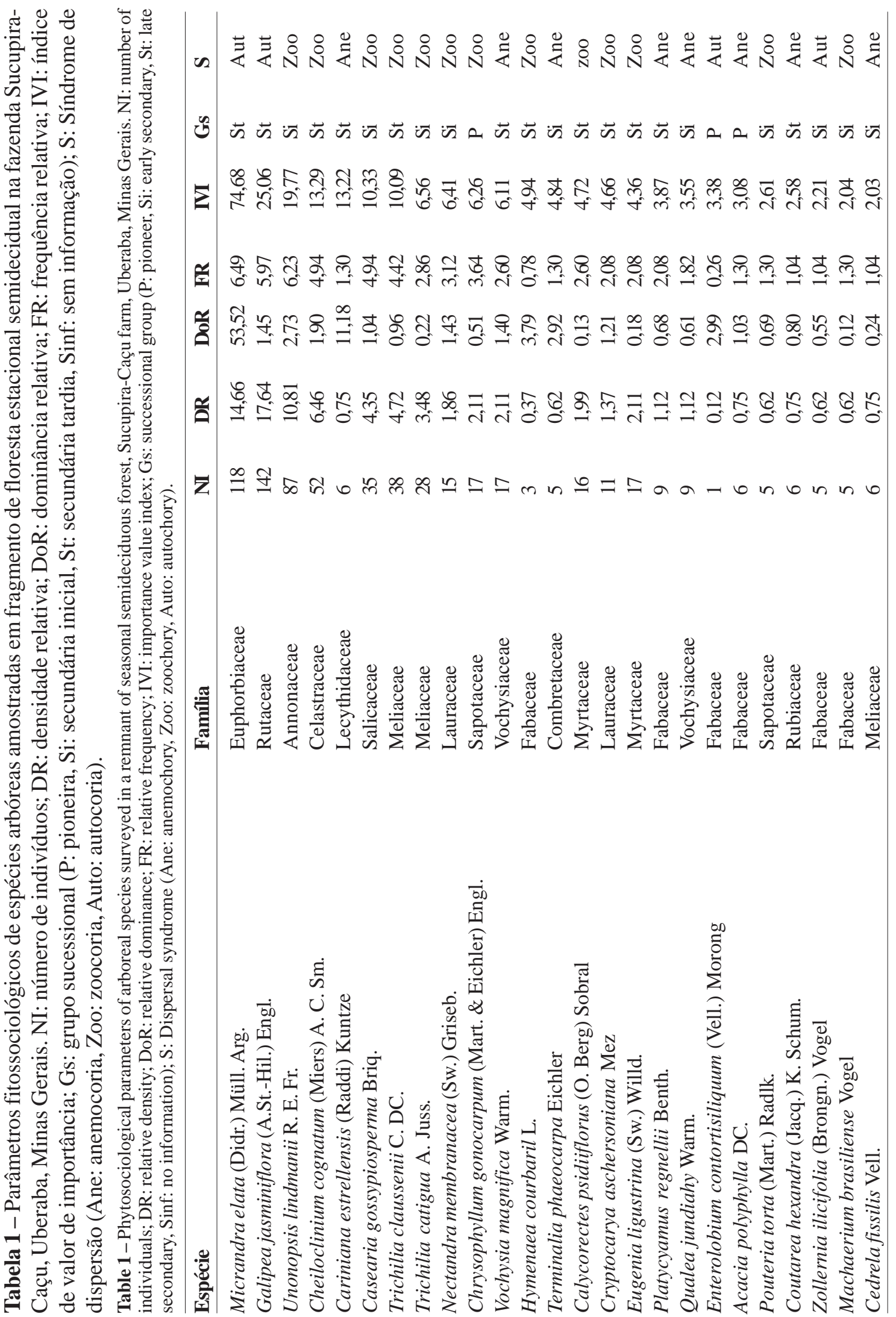




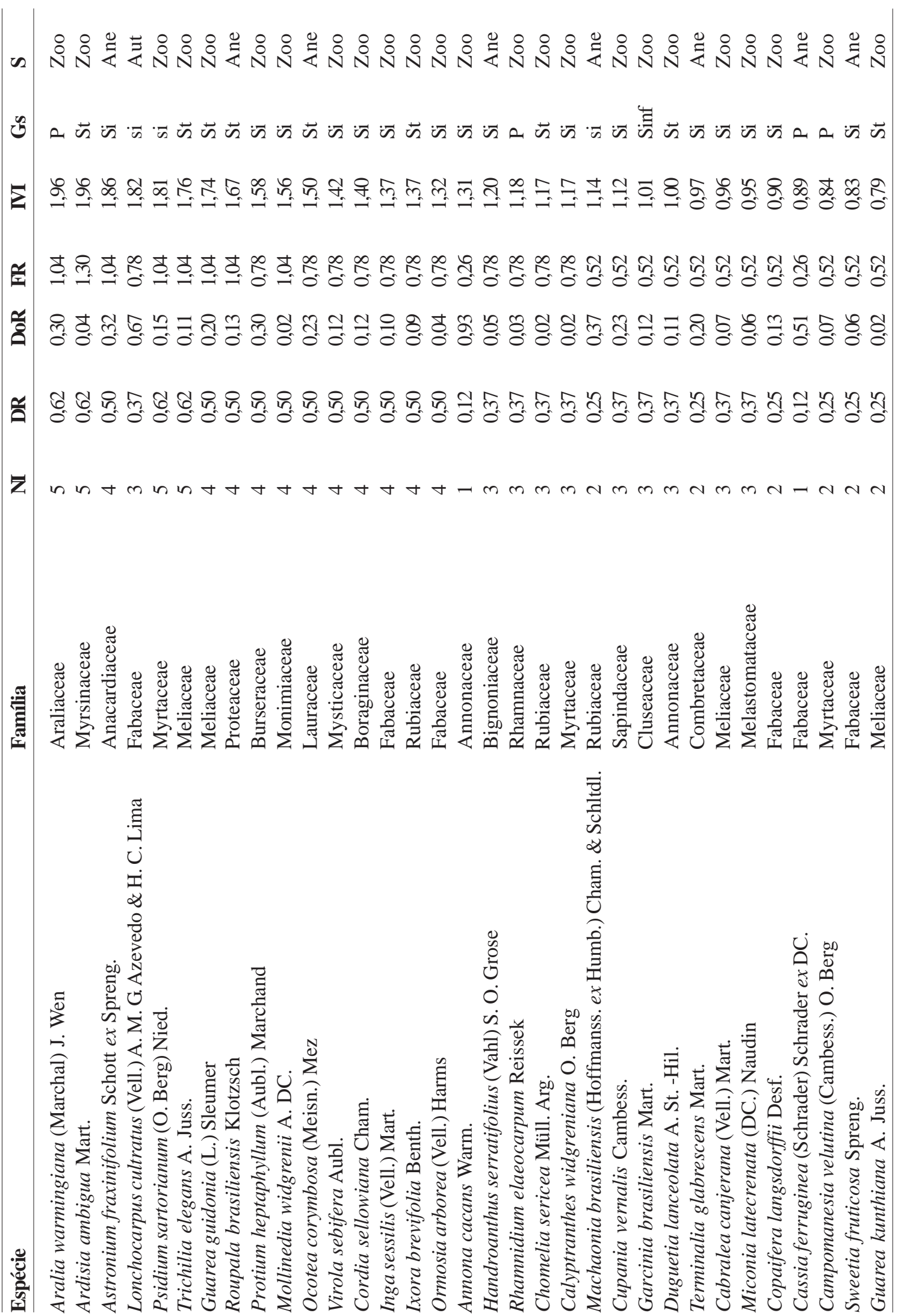




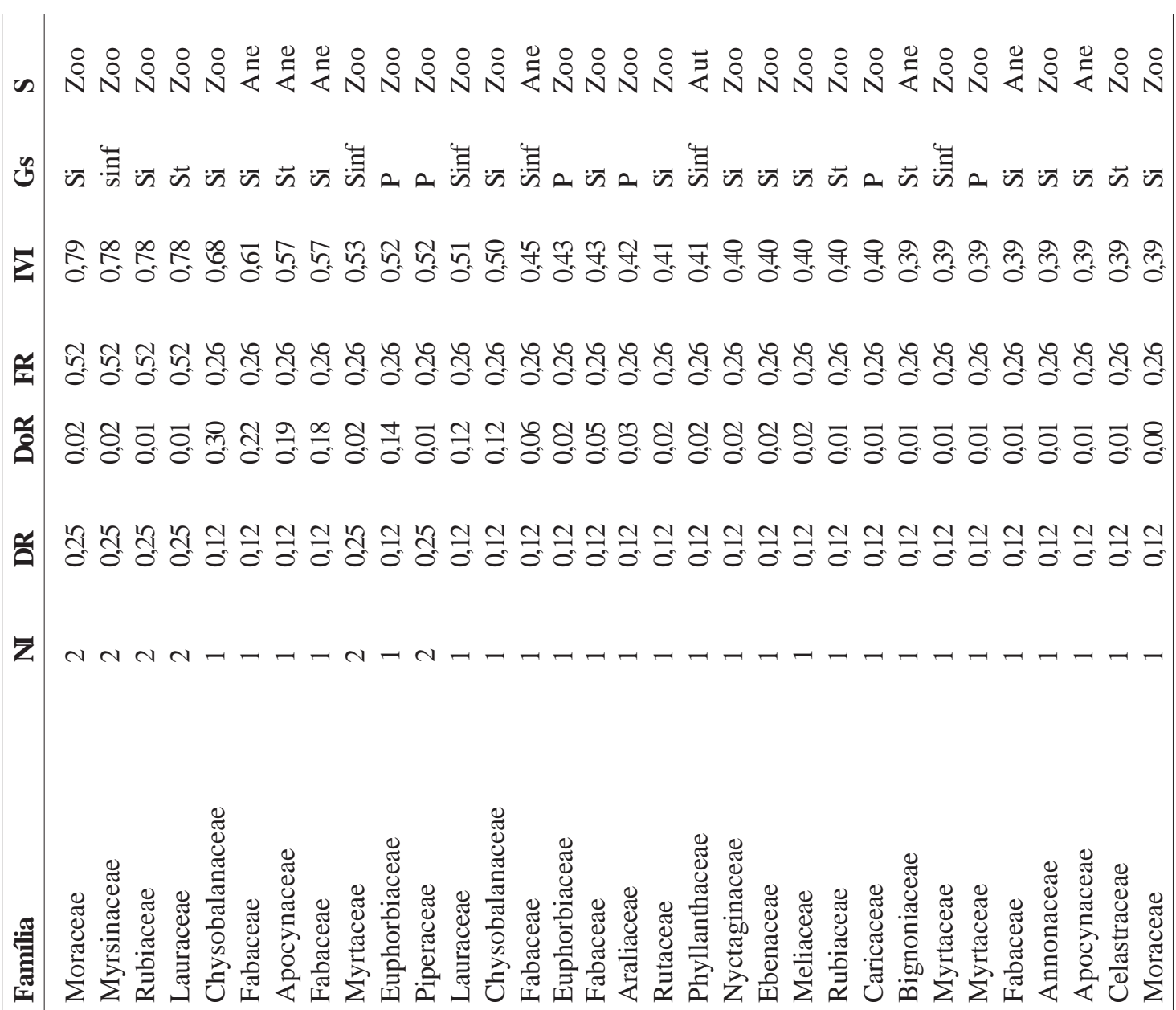

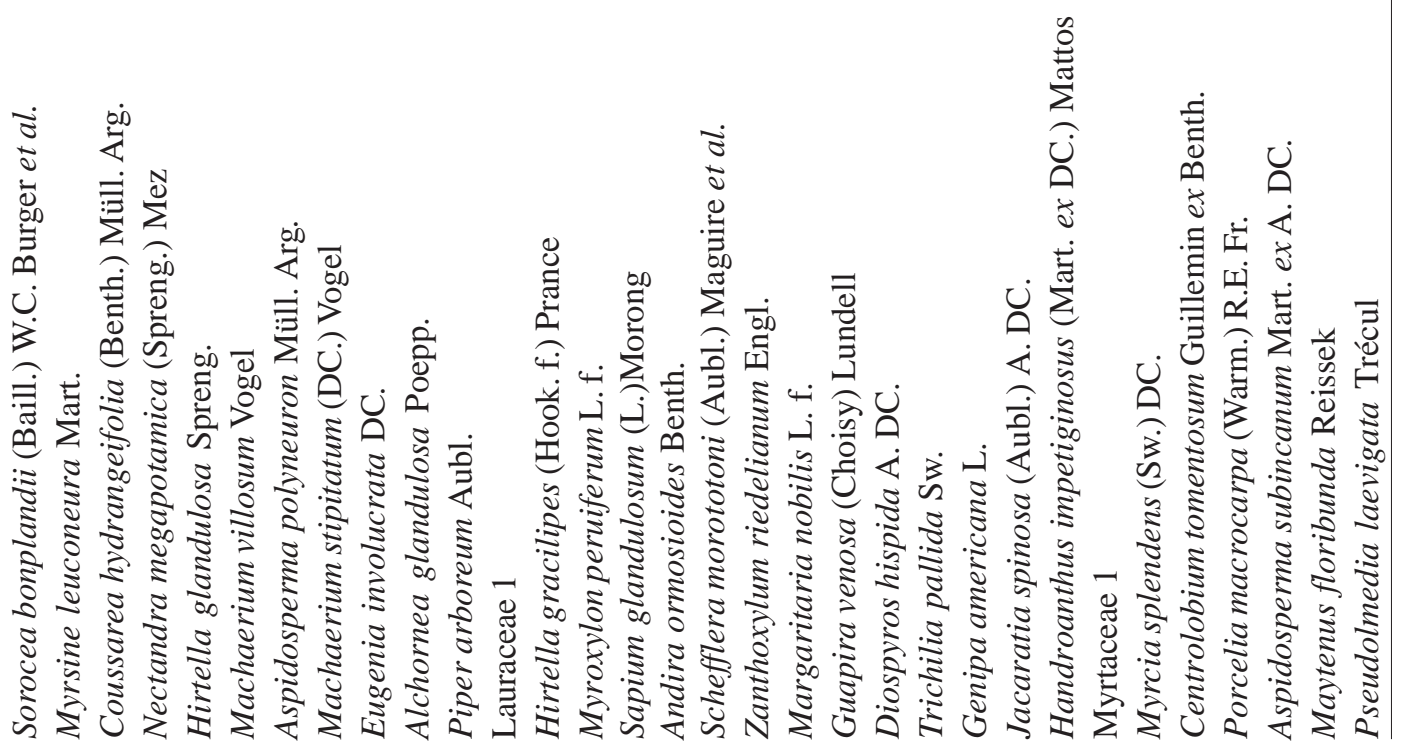


vegetação. Geralmente, florestas primárias apresentam maior número de árvores com altos valores de área basal, enquanto aquelas em estágios mais iniciais de regeneração formam grandes adensamentos de árvores com pequenos diâmetros (Uhl \& Murphy 1981; Parthasarathy 1999). No caso da floresta estacional da fazenda Sucupira - Caçu, o valor de densidade total (805 indivíduos.ha-1 ${ }^{-1}$ não muito elevado, aliado ao alto valor alcançado para área basal total $\left(45,8 \mathrm{~m}^{2} \cdot \mathrm{ha}^{-1}\right)$, são indicadores do estágio sucessional avançado da comunidade estudada.

A elevada área basal do fragmento estudado é fato pouco comum, quando comparada com os valores de área basal em outros estudos em FES. Esse valor é consideravelmente superior aos encontrados em estudos realizados na região do Triângulo Mineiro (Kilka 2007; Vale 2008; Gusson et al. 2009) e aos demais utilizados para comparação (Tab. 2). Valores semelhantes para área basal só foram encontrados em levantamentos realizados em floresta atlântica, como os relatados por Kurtz
\& Araujo (2000) $\left(57,28 \mathrm{~m}^{2} / \mathrm{ha}\right)$ e por Moreno et al. (2003) (41,9 $\mathrm{m}^{2} / \mathrm{ha}$.), em grande parte devido aos altos valores alcançados para a densidade absoluta, nesses estudos.

A área basal de um indivíduo pode ser um estimador da idade em espécies nativas florestais. Assim, enquanto as áreas maduras possuem muitas árvores com troncos de grande diâmetro e dominantes, com espécies de grupos sucessionais tardios, de grande longevidade e crescimento lento e contínuo, as áreas em sucessão possuem poucas árvores de grande porte e acentuada densidade de indivíduos de pequeno porte com espécies de grupos sucessionais iniciais, crescimento rápido e com taxa de renovação de indivíduos e espécies mais alta. (Nunes et al. 2003).

É característico, em muitas florestas, um pequeno número de espécies com alta densidade (Parthasarathy 1999) e um grande número de espécies com baixa densidade (Hartshorn 1980). Isto foi observado neste estudo, onde um total de 68 $(63,1 \%)$ das 90 espécies amostradas apresentou densidade inferior a cinco indivíduos

Tabela 2 - Informações gerais sobre as áreas usadas para o cálculo de similaridade florística (S: Número de espécies; Dens.: densidade; ind.: indivíduos).

Table 2 - General information on the areas included in the floristic similarity analysis (S: Number of species; Dens.: density, ind.: individuals).

\begin{tabular}{|c|c|c|c|c|c|c|}
\hline Área & Município & $\begin{array}{c}\text { Área } \\
\text { amostrada }\end{array}$ & (S) & $\begin{array}{c}\text { Dens. } \\
(\text { ind. ha } \\
\end{array}$ & $\begin{array}{c}\text { Área basal } \\
\left(\mathrm{m}^{2} \mathrm{ha}^{-1}\right)\end{array}$ & Autor \\
\hline Ipi & Ipiaçu, MG & 1,0 & 53 & 837 & 15,14 & Gusson, et al.(2009) \\
\hline Udi1 & Uberlândia, MG & 1,0 & 88 & 880 & 26,19 & A. R.S. Neto, dados não publicados \\
\hline Udi2 & Uberlândia,MG & 1,2 & 92 & 1218 & 24,29 & Kilka (2007) \\
\hline Udi3 & Uberlândia, MG & 1,2 & 116 & 1556 & 23,90 & Lopes et al. (2008) \\
\hline Lum & Luminárias,MG & 1,3 & 159 & 1830 & 28,33 & Rodrigues et al. (2003) \\
\hline Per & Carrancas,MG & 1,2 & 217 & 2138 & 34,16 & Oliveira-Filho et al. (2004) \\
\hline SCar & São Carlos,SP & 1,0 & 77 & 1239 & 25,34 & Silva \& Soares (2002) \\
\hline Caet & Gália,SP & 0,6 & 62 & 1080 & 31,00 & Durigan et al. (2000) \\
\hline R Doc & Rio Doce, $\mathrm{MG}$ & 0,5 & 143 & 1569 & 26,94 & Lopes et al. (2002) \\
\hline Viç1 & Viçosa, MG & 0,5 & 151 & 1640 & 38,45 & Campos et al. (2006) \\
\hline Viç2 & Viçosa, MG & 0,5 & 124 & 2550 & 28,70 & Silva et al. (2004) \\
\hline Lav1 & Lavras, MG & 2,1 & 175 & 1500 & 27,24 & Espírito Santo et al. ( 2002) \\
\hline Lav2 & Lavras, MG & 1,2 & 157 & 1115 & 29,14 & Machado et al. (2004) \\
\hline Ara & Araguari, MG & 1,0 & 79 & 839 & 26,69 & Vale (2008) \\
\hline Bos JK & Araguari, MG & 1,2 & 113 & 1522,5 & 32,89 & Araújo et al. (1997) \\
\hline Uber & Uberaba, MG & 1,0 & 90 & 805 & 45,80 & Este estudo \\
\hline
\end{tabular}


e 29 espécies (32,2\% do total) apresentaram apenas um indivíduo amostrado (Tab. 1).

As espécies com baixa densidade somaram apenas 71 indivíduos ( $8,8 \%$ do total). No entanto, o conjunto das espécies pouco abundantes pode ter uma importância ecológica e ser responsável por diversas funções no ecossistema, como aumentar a resistência da comunidade contra invasores e retenção de nutrientes (Lyons et al. 2005).

\section{Similaridade florística}

O dendrograma confeccionado a partir das análises de agrupamento, baseado no coeficiente de Sørensen entre 16 áreas, evidenciou a formação de quatro grupos com valores de similaridade superiores a 0,35 (Fig. 1). Alguns agrupamentos apresentaram valores de similaridade menores do que 0,5 , usualmente considerado como limite inferior para indicar semelhança na composição florística entre áreas comparadas e, nesses casos ressaltam a diversidade espacial da composição florística entre as áreas de mesma formação vegetacional. Mesmo assim, para efeito de comparações da área de estudo com estudos realizados em diferentes regiões, optou-se por interpretar os principais agrupamentos formados: o grupo G1, formado pelas florestas estudadas do Triângulo Mineiro, o G2 pelas florestas estudadas no estado de São Paulo, o G3 e o G4 pelas áreas estudadas no sudeste e no sul de Minas Gerais, respectivamente.

Os grupos formados com o uso do coeficiente de similaridade de Sørensen reuniram áreas mais próximas geograficamente. Dessa forma pode-se inferir que a proximidade geográfica entre formações vegetais semelhantes é um fator importante para determinar as espécies existentes nos fragmentos. Já foi verificado que a similaridade declina com o distanciamento entre áreas amostrais (McDonald et al. 2005).

O grupo G1 foi formado por áreas do Triângulo Mineiro que foram estudadas com uma metodologia de amostragem similar. Dentro de G1 observou-se a formação de um subgrupo, o G1.1, formado pelas matas de Araguari (Vale 2008) e a de Uberaba (este estudo), com similaridade superior a 0,5. Este

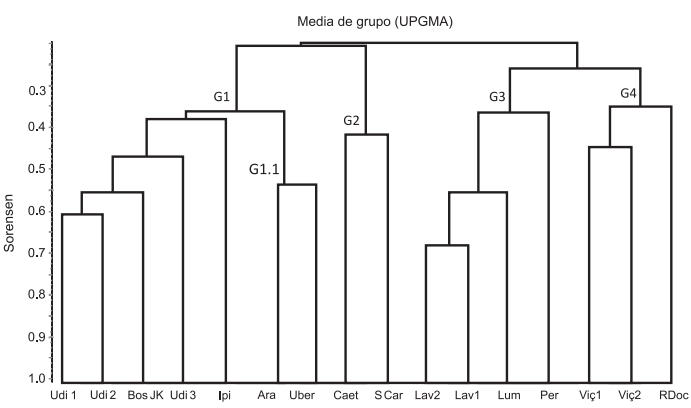

Figura 1 - Análise de agrupamento de áreas de floresta estacional semidecidual do sudeste brasileiro, no nível taxonômico de espécies. (G1: Triângulo Mineiro; G1.1: Uberaba e Araguari; G2: São Paulo; G3: sul de Minas Gerais, G4: sudeste de Minas Gerais.). Lav1: Espírito-Santo et al. 2002; Lav2: Machado et al. 2004; Lum: Rodrigues et al. 2002; Per: Oliveira-Filho et al. 2004; Viç1: Campos et al. 2006; Viç2: Silva et al. 2004; RDoc: Lopes et al. 2002; Caet: Durigan et al. 2000; SCar: Silva \& Soares 2002; Udi1: A. R.S. Neto, dados não publicados; Udi2: Kilca 2007; Udi3: Lopes et al. 2008; Ipi: Gusson et al.2009; Ara: Vale 2008; Bos JK: Araújo et al. 1997;Uber: Este estudo.

Figure 1 - Cluster analysis of seasonal semideciduous forests from southeastern Brazil, at taxonomic level of species. (G1: Triângulo Mineiro; G1.1: Uberaba and Araguari; G2: São Paulo; G3: southern Minas Gerais, G4: southeastern Minas Gerais). Lav1: Espírito Santo et al. 2002; Lav2: Machado et al. 2004; Lum: Robinson et al. 2002; Per: Oliveira-Filho et al. 2004; Viç1: Campos et al. 2006; VIC2: Silva et al. 2004; RDoc: Lopes et al. 2002; Caet: Durigan et al. 2000; SCar: Smith \& Smith 2002; Udi1: A.R.S Neto, unpublished data; Udi2: Kilca 2007; Udi3: Lopes et al. 2008; Ipi: Gusson et al.2009; Ara: Vale 2008; Bos JK: Araújo et al. 1997; Uber: This study.

grupo apresentou 118 espécies no total e 44 espécies em comum.

A similaridade florística entre as floresta de Araguari (Vale 2008) e Uberaba (este estudo) (G1.1) pode ser explicada pelo conjunto de espécies com ocorrência apenas nessas duas áreas e pela constatação de que estas são as áreas que apresentam o melhor estado de conservação, dentre as matas que formaram o G1, possivelmente apresentando um maior número de espécies características de floresta madura. As espécies que aparecem exclusivamente nessas duas áreas são: Aralia warmingiana, Ardisia ambigua, Aspidosperma polyneuron, Calycorectes psidiiflorus, Chomelia sericea, Chrysophyllum gonocarpum, Guarea kunthiana, Jacaratia spinosa, Lonchocarpus cultratus, Miconia latecrenata, Trichilia claussenii e Zollernia ilicifolia. 
Trichillia elegans, Sweetia fruticosa, Ardisia ambigua e Zollernia ilicifolia, que ocorreram na floresta estudada, são consideradas associadas com florestas pluviais de Mata Atlântica (Oliveira-Filho \& Fontes 2000). As duas primeiras espécies são encontradas em FES (Oliveira-Filho \& Fontes 2000), apresentando ampla distribuição pelas florestas do sudeste brasileiro. No entanto, a presença de A. ambigua e Z. ilicifolia (cada uma com cinco indivíduos na área de estudo), sugere uma possível ligação, no passado, desta área com as formações mais úmidas da Mata Atlântica.

Apenas Acacia polyphylla, Cariniana estrellensis, Casearia gossypiosperma, Chrysophyllum gonocarpum, Cupania vernalis, Guarea kunthiana, Inga sessilis, Rhamnidium elaeocarpum e Trichilia pallida ocorrem em todos os grupos formados. Algumas dessas espécies (C. estrellensis e C. vernalis) são consideradas de ocorrência abrangente, com ampla distribuição em FES do sudeste brasileiro (Oliveira-Filho \& Fontes 2000). Outras duas espécies são encontradas com abundância significativa em florestas estacionais deciduais (A. polyphylla e $R$. elaeocarpum). Por outro lado, C. gonocarpum, A. polyphylla e $T$. pallida foram frequentes em estudos realizados em Mata Atlântica (Bertani et al. 2001; Nascimento et al. 1999). Apenas G. kunthiana demonstrou ser mais restrita à FES (Oliveira-Filho \& Fontes 2000).

A comunidade arbórea em áreas de FES é muito variável quanto à composição de espécies, o que aumenta a importância destas florestas para conservação da biodiversidade, principalmente pelo fato de que uma única área apresenta apenas uma pequena proporção do total de espécies já relatadas para essas formações.

Micrandra elata, a espécie mais importante no presente estudo, não foi encontrada nas outras áreas consideradas para comparações florísticas, com exceção do Bosque John Kennedy, Araguari, MG (Araújo et al. 1997), onde ocorreu com o segundo maior IVI, e em florestas de São Paulo estudadas por Silva \&
Soares (2002). Porém, existem registros de ocorrência dessa espécie nas Guianas, na Colômbia e no Peru, além do Brasil (http:// mobot.mobot.org/W3T/Search/vast.html). A grande abundância da espécie na floresta estudada não tem uma explicação clara até o momento e pode ser atribuída a algum fator histórico que possibilitou a sua chegada e estabelecimento, com grande sucesso, no remanescente em questão.

Os registros de ocorrência florística e padrões de dominância demonstram o quanto a vegetação da floresta estudada em Uberaba é única, no contexto das demais áreas de floresta estacional semidecidual até então estudadas no Triângulo Mineiro. Em um hectare de vegetação arbórea foram encontradas desde espécies características de formações úmidas da Mata Atlântica, até espécies que podem ser encontradas em florestas úmidas das Guianas, Colômbia e Peru. Tal singularidade pode ser um indicador de que esta vegetação tenha sido mais úmida no passado, com ligação direta, por alguns rios da bacia do Paraná, com a Mata Atlântica do leste do Brasil. Estes indícios aumentam a importância para preservação dos raros fragmentos florestais ainda em bom estágio de conservação, para que estudos posteriores possam investigar melhor a conexão de ilhas de FES imersas no domínio do Cerrado com demais formações úmidas adjacentes.

A proporção de espécies em cada síndrome de dispersão, com predomínio de zoocoria (58 espécies, 64\%) sobre anemocoria (23 espécies, 26\%) e autocoria (sete espécies, $8 \%$ ), é similar às encontradas em outros estudos realizados em florestas tropicais (Morellato \& Leitão-Filho 1992; Rossi 1994). Porém, quando analisamos o número de indivíduos em cada síndrome, a autocoria tem um aumento na representatividade, passando a 34\% dos indivíduos amostrados. Esse fato se deve ao grande número de indivíduos de Galipea jasminiflora e Micrandra elata, espécies com os maiores valores de densidade absoluta na comunidade. Toniato \& OliveiraFilho (2004) relatam que a autocoria ocorreu 
com maior frequência em florestas secundárias, o que parece não ser o caso da área estudada, já que o fragmento encontra-se bem conservado e em estágio avançado de sucessão.

O predomínio de espécies zoocóricas também foi observado por Santos \& Kinoshita (2003). Zoocoria foi a principal síndrome encontrada por Yamamoto (2001) em floresta estacional semidecidual montana no estado de São Paulo. No presente estudo foi observado o predomínio de espécies anemocóricas no estrato superior da floresta, o que é esperado para espécies que dependem do vento para dispersão, enquanto que a zoocoria foi melhor representada nos estratos inferiores. Segundo Roth (1987), unidades de dispersão zoocóricas, com frutos ou sementes pesadas e numerosas, tendem a predominar nos estratos mais baixos da floresta, nos quais a vida animal seria mais intensa. Roth (1987) e Killeen et al. (1998), entre outros, também observaram que o tipo predominante de dispersão difere entre os estratos verticais em florestas tropicais. Morellato \& Leitão Filho (1992) encontraram diferenças entre os tipos de dispersão predominantes em cada estrato de fragmentos da FES no sudeste brasileiro.

Quanto à classificação das espécies em categorias sucessionais, ocorreu uma maior porcentagem de espécies secundárias iniciais, que representaram $46 \%$ da comunidade. As espécies secundárias tardias representam $32 \%$ e as espécies pioneiras 13\% (9\% sem informação). Quando analisamos a porcentagem de indivíduos, as pioneiras apresentaram 5\%, as secundárias iniciais $33 \%$ e as secundárias tardias $60 \%$ (2\% sem informação). Segundo Budowski (1965), as espécies pioneiras e secundárias iniciais são encontradas em áreas com condições climáticas e edáficas muito diferentes, o que lhes propicia ampla distribuição geográfica. Esse mesmo autor cita também que em florestas fechadas, não perturbadas, ou em estádios sucessionais mais avançados, o recrutamento dessas espécies está condicionado ao surgimento de clareiras. Assim, possivelmente as espécies pioneiras que apareceram na amostragem são resultado de alguma clareira aberta no passado, visto que são indivíduos mais velhos, que provavelmente entraram na comunidade em um tempo pretérito e ainda permanecem na comunidade.

A comunidade arbórea do presente estudo apresenta características que a distinguem, quanto à classificação sucessional das espécies que a compõem, de outras florestas estacionais semideciduais estudadas no Triângulo Mineiro, com maior abundância de indivíduos e espécies secundárias tardias e baixa densidade de espécies pioneiras.

Com base no alto valor aferido para a área basal, grande número de indivíduos de grande porte e predominância de espécies pertencentes aos grupos sucessionais tardios, considera-se que esta fitocenose pode ser classificada como um remanescente de floresta estacional semidecidual madura, sem indícios de perturbação, que a diferencia de outras florestas remanescentes na região. Tais singularidades estruturais e florísticas ressaltam a importância da área para a conservação da biodiversidade e devem ser levados em conta como incentivo para a criação de uma unidade de conservação de caráter permanente, já que, atualmente, o fragmento é parcialmente protegido como parte da reserva legal da propriedade.

\section{Agradecimentos}

Os autores agradecem à FAPEMIG (CRA-00694/08) pelo suporte financeiro para realização e divulgação do trabalho; ao Dr. Glein Monteiro de Araújo pelo apoio no campo e valiosas sugestões em todas as fases de realização das análises e ao Sr. Alexandre, proprietário da Fazenda Sucupira-Caçu, por gentilmente permitir o acesso à área de estudo.

\section{REFERÊNCIAS BIBLIOGRÁFICAS}

Abdala, V.L. 2005. Zoneamento ambiental da bacia do alto curso do rio Uberaba-MG como subsídio para gestão do recurso hídrico superficial. Dissertação de Mestrado. Universidade Federal de Uberlândia, Uberlândia. 73p.

Araújo, G.M.; Guimarães, A.J.M. \& Nakajima, J.N. 1997. Fitossociologia de um remanescente de 
mata mesófila semidecídua urbana, Bosque John Kennedy, Araguari, MG, Brasil. Revista Brasileira de Botânica 20(1): 67-77.

Araújo, G.M. \& Haridasan, M. 1997. Estrutura fitossociológica de duas matas mesófilas semidecíduas, em Uberlândia, Triângulo Mineiro. Naturalia 22: 115-129.

Bertani, D.F.; Rodrigues, R.R.; Batista, J.L. \& Sheperd, G.J. 2001. Análise temporal da heterogeneidade florística e estrutural em uma floresta ribeirinha. Revista Brasileira de Botânica 24(1): 11-23.

Brower, J.E.; Zar, J.H. \& con Ende, C.N. 1998. Field and laboratory methods for general ecology. 4nd ed. Massachusetts, WCB McGraw-Hill NY. 273p.

Budowski, G. 1965. Distribution of tropical american rain forest species in the light of successional processes. Turrialba 15(1): 40-42.

Campos, E.P.; Silva, A.F.; Meira Neto, J.A.A. \& Martins, S.V. 2006. Florística e estrutura horizontal da vegetação arbórea de uma ravina em um fragmento florestal no município de Viçosa, MG. Revista Árvore 30(6): 1045-1054.

Durigan, G.; Franco, G.A.D.C.; Saito, M. \& Baitello, J.B. 2000. Estrutura e diversidade do componente arbóreo da floresta na Estação Ecológica dos Caetetus, Gália, SP. Revista Brasileira de Botânica 23(4): 371-383.

Eiten, G. 1982. Brazilian 'savannas'. In: Huntley, B.J. \& Walker, B.H. (eds.). Ecology of tropical savannas. Springer-Verlag, Berlin. Pp. 25-48.

Espírito-Santo, F.D.B.; Oliveira-Filho, A.T.; Machado, E.L.M.; Fontes, M.A.L. \& Marques, J.J.G.S.M. 2002. Variáveis ambientais e a distribuição de espécies arbóreas em um remanescente de floresta estacional semidecídua montana no campus da Universidade Federal de Lavras, MG. Acta Botanica Brasilica 16(3): 331-356.

Gandolfi, S.; Leitão-Filho, H.F. \& Bezerra, C.L. 1995. Levantamento Florístico e caráter sucessional das espécies arbustivo-arbóreas de uma floresta mesófila semidecídua no município de Guarulhos, SP. Revista Brasileira de Biologia 55(4): 752-767.

Gusson, A.E.; Lopes, S.F.; Dias-Neto, O.C.; Vale, V.S.; Oliveira, A.P. \& Schiavini, I. 2009. Características químicas do solo e estrutura de um fragmento de floresta estacional semidecidual em Ipiaçu, Minas Gerais, Brasil. Rodriguésia 60 (2): 403-414.
Hartshorn, G.S. 1980. Neotropical forest dynamics. Biotropica 12: 23-30

IBGE. 1993. Mapa de vegetação do Brasil. Departamento de Cartografia DECAR/DEDIT/ CDDI. Escala1:5.000.000 - IBGE - IBAMA, Rio de Janeiro.

Kilca, R.V. 2007. Padrões florísticos, estruturais e relações edáficas entre dois tipos de florestas tropicais estacionais no Cerrado. Dissertação de Mestrado. Programa de Pós-graduação em Ecologia e Conservação de Recursos Naturais. Universidade Federal de Uberlândia. Uberlândia, MG. 64p.

Killeen, T.J.; Jardim, A.; Mamani, F. \& Rojas, N. 1998. Diversity, composition and structure of a tropical semideciduous forest in the Chiquitanía region of Santa Cruz, Bolivia. Journal of Tropical Ecology 14: 803-827.

Kurtz, B. C. \& Araújo, D. S. D. 2000. Composição florística e estrutura do componente arbóreo de um trecho de Mata Atlântica na Estação Ecológica Estadual do Paraíso, Cachoeiras de Macacu, Rio de Janeiro, Brasil. Rodriguésia 51(78/79): 69-111.

Leitão-Filho, H.F. 1987. Considerações sobre a florística de florestas tropicais e subtropicais do Brasil. IPEF 35: 41-46

Leitão-Filho, H.F. 1992. A flora arbórea da Serra do Japi. In: Morellato, L.P.C. (org.). História natural da Serra do Japi - ecologia e preservação de uma área florestal no sudeste do Brasil. EDUNICAMP, Campinas. Pp. 40-62.

Lopes, S.F.; Oliveira, A.P.; Dias Neto, O.C.; Vale, V.S.; Gusson A.E. \& Schiavini, I. 2008. Estrutura e grupos ecológicos em uma floresta estacional semidecidual em Uberlândia, MG. In: II Simpósio Internacional Savanas Tropicais e IX Simpósio Nacional Cerrado, 2008, Brasília. Simpósio Cerrado Anais. EMBRAPA Cerrados, Planaltina. Pp. 1-7.

Lopes, W.P.; Silva, A.F.; Souza, A.L. \& Meira Neto, J.A. 2002. Estrutura fitossociológica de um trecho de vegetação arbórea no parque estadual do Rio Doce - Minas Gerais, Brasil. Acta Botanica Brasilica 16(4): 443-456.

Lyons, K.G.; Brigham, C.A.; Traut, B.H. \& Schwartz, M.W.2005. Rare species and ecosystem functioning. Conservation Biology 19(4): 1019-1024.

Machado, E.L.M.; Oliveira-Filho, A.T.; Carvalho, W.A.C.; Souza, J.S.; Borém, R.A.T. \& Botezelli, L. 2004. Análise comparativa da estrutura e 
flora do compartimento arbóreo-arbustivo de um remanescente florestal na Fazenda Beira Lago, Lavras, MG. Revista Árvore 28(4): 499-516.

McDonald, R.; McKight, M.; Weiss, D.; Selig, E.; O'Connor, M.; Violin, C. \& Moody, A. 2005. Species compositional similarity and ecoregions: Do ecoregion boundaries represent zones of high species turnover? Biological Conservation 126: 24-40.

Morellato, L.P.C. \& Leitão-Filho, H.L.F. 1992. Padrões de frutificação e dispersão na Serra do Japi. In: Morellato, L. P. (ed.). História natural da Serra do Japi - ecologia e preservação de uma área florestal no Sudeste do Brasil. Campinas, Editora da UNICAMP. Pp 112-141.

Moreno, M.R.; Nascimento, M.T. \& Kurtz, B.C. 2003. Estrutura e composição florística do estrato arbóreo em duas zonas altitudinais na Mata Atlântica de encosta da região do Imbé, RJ. Acta Botanica Brasilica 17(3): 371-386.

Nascimento, H.E.M.; Dias, A.S.; Tabanes, A.A.J. \& Viana, V.M. 1999. Estrutura e dinâmica de populações arbóreas de um fragmento de floresta estacional semidecidual na região de Piracicaba, SP. Revista Brasileira de Biologia 59(2): 329-342.

Nunes, Y.R.F.; Mendonça, A.V.R.; Botzelli, L.; Machado, E.L.M. \& Oliveira-Filho, A.T. 2003. Variações da fisionomia, diversidade e composição de guildas da comunidade arbórea em um fragmento de floresta semidecidual em Lavras, MG. Acta Botanica Brasilica 17(2): 213-229.

Oliveira-Filho, A.T. \& Fontes, M.A. 2000. Patterns of floristic differentiation among atlantic forests in Southern Brazil and the influence of climate. Biotropica 32(4b): 793-810.

Oliveira-Filho, A.T. \& Machado, J.N.M. 1993. Composição florística de uma floresta semidecídua montana, na Serra de São José, Tiradentes, MG. Acta Botanica Brasilica 7: 71-88.

Oliveira-Filho, A.T.; Carvalho, A.C.; Fontes, M.A.L.; Berg, E.V.D.; Curi, N. \& Carvalho, W.A.C. 2004. Variações estruturais do componente arbóreo de uma floresta semidecídua alto-montana na chapada das Perdizes, Carrancas, MG. Revista Brasileira de Botânica 27(2): 291-309.

Parthasarathy, N. 1999. Tree diversity and distribution in undisturbed and human-impacted sites of tropical wet evergreen forest in southern Western Ghats, India. Biodiversity and Conservation 8(4): 1365-1381.
Paula, A.; Silva, A.F.; Marco Júnior, P.; Santos, F.A.M. \& Souza, A.L. 2004. Sucessão ecológica da vegetação arbórea em uma floresta estacional semidecidual, Viçosa, MG, Brasil. Acta Botanica Brasilica 18(3): 407-423.

Rizzini, C. 1979. Tratado de fitogeografia do Brasil. vol.2. Aspectos sociológicos e florísticos. Hucitec/EdUSP, 375p.

Rodrigues, L.A.; Carvalho, D.A.; Oliveira Filho, A.T.; Botrel, R.T. \& Silva, E.A. 2003. Florística e estrutura da comunidade arbórea de um fragmento florestal em Luminárias, MG. Acta Botanica Brasilica 17(1): 71-87.

Rosa, A.G. \& Schiavini, I. 2006. Estrutura da comunidade arbórea em remanescente florestal urbano (Parque do Sabiá, Uberlândia, Minas Gerais). Bioscience Journal 22(1). 151-162.

Rossi, L. 1994. A flora arbórea-arbustiva da mata da reserva da Cidade Universitária "Armando de Salles Oliveira” (São Paulo, Brasil). Boletim do Instituto de Botânica n. 9. Pp. 1-105.

Roth, I. 1987. Stratification of a tropical forest as seen in dispersal types. Dr W. Junk Publishers, Dordrecht.

Santos, K; Kinoshita L. S. 2003. Flora arbustivoarbórea do fragmento de floresta estacional semidecidual do Ribeirão Cachoeira, município de Campinas, SP. Acta Botanica Brasilica 17(3): 325-341.

Shepherd, G.J. 2007. FITOPAC-SHELL v.1.6.1.29. Universidade Estadual de Campinas, Campinas. 78p.

Silva, L.A. \& Soares, J.J. 2002. Levantamento fitossociológico em um fragmento de floresta estacional semidecídua, no município de São Carlos, SP. Acta Botanica Brasilica 16(2): 205-216.

Silva, V.F.; Venturini, N.; Oliveira-Filho, A.T.; Macedo, R.L.G.; Carvalho, W.A.C. \& Berg, E.V. 2003. Caracterização estrutural de um fragmento de floresta semidecídua no município de Ibiturana, MG. Cerne 9(1): 92-106.

Silva, N.R.S.; Martins, S.V.; Meira Neto, J.A.A. \& Souza, A. L. 2004. Composição florística e estrutura de uma floresta estacional semidecidual montana em Viçosa, MG. Revista Árvore 28(3): 397-405.

Silva, L.A. \& Soares, J.J. 2003. Composição Florística de um Fragmento de Floresta Estacional Semidecídua no Município de São Carlos- SP. Revista Árvore 97(5): 647-656.

Souza, V.C. \& Lorenzi, H. 2005. Botânica sistemática: guia ilustrado para identificação das famílias de 
Angiospermas da flora brasileira, baseado em APG II. Instituto Plantarum, Nova Odessa. 640p. Scolforo J.R.; Carvalho, L.M.T.; Oliveira, A.D.; Mello, J.M.; Oliveira, L.T.; Junior, F.W.A.; Cavalcanti, H.C. \& Vargas-Filho, R. 2006. Procedimentos para mapeamento. In: Scolforo, J.R. \& Carvalho, L.M.T. (eds.). Mapeamento e inventário da flora nativa dos reflorestamentos de Minas Gerais. UFLA, Lavras. 288p.

Toniato, M.T.Z. \& Oliveira-Filho, A.T. 2004. Variations in tree community composition and structure in a fragment of tropical semideciduous forest in southeastern Brazil related to different human disturbance histories. Forest Ecology and Management 198: 319-339.

Uhl, C. \& Murphy, P.G. 1981. Composition, structure, and regeneration of a "tierra firme" forest in the
Amazon Basin of Venezuela. Tropical Ecology 22(2): 219-237.

Vale, V.S. 2008. Padrões e processos ecológicos do componente arbóreo em uma área de Floresta Estacional Semidecidual (Araguari, MG). Dissertação de Mestrado. Universidade Federal de Uberlândia. Uberlândia. 91p.

Veloso, P.H.; Rangel-Filho, A.L.R. \& Lima, J.C.A. 1991. Classificação da vegetação brasileira adaptada a um sistema universal. IBGE, Rio de Janeiro. 123p.

Yamamoto, L.F.; Kinoshita, L.S. \& Martins, F.R. 2007. Síndromes de polinização e de dispersão em fragmentos da Floresta Estacional Semidecídua Montana, SP, Brasil. Acta Botanica Brasilica 21(3): 553-573. 